\title{
Ocorrência de doenças do tomateiro na região de Guanambi, BA
}

\section{Occurrence of diseases in tomato in the region of Guanambi, Bahia}

\author{
Macelle Amanda Silva Guimarães ${ }^{1}$, Jessica Hellen dos Santos Teixeira ${ }^{2}$, Suane Coutinho Cardoso ${ }^{* 3}$
}

Resumo: As doenças do tomateiro são responsáveis por grandes prejuízos econômicos e a falta de conhecimento técnico no diagnóstico e controle dessas doenças onera os custos e limitam a sua produção. Esse trabalho tem como objetivo realizar um levantamento para identificação e registro de ocorrência de doenças do tomateiro na região de Guanambi, BA. O levantamento foi realizado nos Distritos de Morrinhos e Guirapá e nos Povoados de Brejos dos Padres e do Tanque. Para tanto, foram realizadas visitas nas áreas produtoras de tomate e para avaliação do histórico da área foi aplicado um questionário aos produtores. Amostras de plantas infectadas foram coletadas e levadas para análise no Laboratório de Fitopatologia do IFBaiano - Campus Guanambi ou enviadas para diagnóstico em Clinica Fitopatológica. Foram diagnosticadas nove doenças bióticas: vira cabeça do tomateiro (Tomato spotted wilt virus), oídio (Oidium sp.), murcha de fusário (Fusarium oxysporum), requeima (Phytophthora infestans), mofo preto (Alternaria alternata), mancha de estenfílio (Stemphylium sp.), mancha de cladospório (Fulvia fulva), pinta-preta (Alternaria solani) e murcha bacteriana (Ralstonia solanacearum); e três doenças abióticas (podridão apical, deficiência de fósforo e murcha por asfixia) nos cultivos de tomate. Dentre as doenças bióticas encontradas, o vira cabeça do tomateiro e o oídio foram as mais frequentes.

Palavras-chaves: Solanum lycopersicum, levantamento doenças, deficiência de cálcio, Tomato spotted wilt virus.

\begin{abstract}
The tomato diseases are responsible for great economic losses and the lack of technical knowledge in the diagnosis and control of these diseases onerous costs and limit their production. This work aims to conduct a survey to identify and record of the tomato diseases occurrence in the Guanambi region, Bahia state. The survey was conducted in Morrinhos, Guirapá, Brejo dos Padres and Tanque Districts. Therefore, visits were made in tomato producing areas and for the evaluation of the area historic have been applied a questionnaire to farmers. Samples of infected plants were collected and sent for analysis at the Laboratory of Phytopathology, IFBaiano - Campus Guanambi or sent for diagnosis in Clinic Phytopathologic. Were diagnosed nine biotic diseases: Tospovirus (Tomato spotted wilt virus), powdery mildew (Oidium sp.), Fusarium wilt (Fusarium oxysporum), late blight (Phytophthora infestans), black mold (Alternaria alternata), Stemphylium leaf blight (Stemphylium sp.), leaf mold (Fulvia fulva), blight (Alternaria solani) and bacterial wilt (Ralstonia solanacearum), and three abiotic diseases (blossom-end rot, phosphorus deficiency and withered by suffocation) in the tomato crops. Among the biotic diseases found, o Tomato spotted wilt virus and Oidium sp. were the most frequent.
\end{abstract}

Key words: Solanum lycopersicum, diseases survey, blossom-end rot, Tomato spotted wilt virus.

\footnotetext{
*Autor para correspondência

Recebido para publicação em 06/10/2015; aprovado em 20/11/2015

${ }^{1}$ Graduanda em Agronomia, Instituto Federal de Educação, Ciência e Tecnologia Baiano - Campus Guanambi, Guanambi- Ba, (77) 3493 2100, macelleamanda@hotmail.com

${ }^{2}$ Graduanda em Agronomia, Instituto Federal de Educação, Ciência e Tecnologia Baiano - Campus Guanambi, jeuhellen@ @otmail.com

${ }^{3}$ D.Sc., Profa. Instituto Federal de Educação, Ciência e Tecnologia Baiano - Campus Guanambi, suane.cardoso@guanambi.ifbaiano.edu.br
} 


\section{INTRODUÇÃO}

O tomate (Solanum lycopersicum) é uma das hortaliças mais cultivadas no Brasil, perdendo apenas para a batata. Essa cultura tem grande importância socioeconômica em todo o país, principalmente nas regiões Sudeste e Centro-Oeste, que são as maiores produtoras (IBGE, 2013; SANTOS et al., 2015). Em 2013, o Brasil produziu 4.187.646 milhões de toneladas de tomate. O Estado de Goiás é o maior produtor nacional, seguidos de São Paulo, Minas Gerais, Paraná e Bahia. Na região Nordeste, a Bahia é o maior produtor, apresentando em 2013 uma produção de 201.842 mil toneladas, o que corresponde a $44 \%$ da quantidade produzida na região (IBGE, 2013).

Essa hortaliça desperta interesse pelos produtores, tanto pela sua aceitação no mercado como pelos preços compensadores (LEAL et al., 2007). No entanto, as doenças do tomateiro são responsáveis por grandes prejuízos econômicos e seu controle juntamente com controle de pragas representam o principal custo de produção da cultura.

Os levantamentos de doenças de plantas são realizados com vários objetivos, entre eles, o desenvolvimento de trabalhos de pesquisa e extensão, elaboração de banco de dados sobre a ocorrência de doenças na região, análise da frequência e da distribuição geográfica de doenças e quantificação de perdas causadas (POZZA et al., 1999). Além disso, esses levantamentos, são importantes para auxiliar na elaboração de estratégias de controle das doenças (BARROSO et al., 2015).

A identificação correta da doença e o conhecimento da sua epidemiologia são pré-requisitos indispensáveis para definir medidas de manejo. Uma diagnose incorreta pode levar a adoção de medidas de controle completamente ineficientes, provocando desde perdas na produção e até danos ambientais (REZENDE et al., 2011).

A região de Guanambi vem aumentando gradativamente sua área de plantio com tomate. Nessa região o plantio é realizado, em sua maioria, por pequenos produtores que cultivam, principalmente, tomate de mesa (estaqueado). No entanto, muitos desses agricultores produzem sem nenhum conhecimento do sistema de produção da cultura, bem como dos seus problemas fitossanitários. Como isso, durante o cultivo se deparam com diferentes sintomas de danos ocasionados por patógenos, pragas e agentes abióticos. E assim, muitas vezes, recorrem a aplicações de defensivos sem os devidos cuidados quanto à identificação correta do agente causal, uso de dosagem e procedimentos de aplicação adequados, podendo gerar danos ambientais, custos desnecessários e perdas na produção.

Considerando a importância da cultura do tomate para a região de Guanambi e a ausência de estudos sobre a ocorrência de doenças do tomateiro nessa região, esse trabalho tem como objetivo realizar um levantamento para identificação e registro de ocorrência de doenças nas áreas produtoras para auxiliar em posterior estabelecimento de medidas efetivas de controle.

\section{MATERIAL E MÉTODOS}

O levantamento de doenças do tomateiro foi realizado nas principais áreas produtoras de tomate da região de Guanambi, BA, no período compreendido entre os meses de agosto de 2012 a abril de 2013. A região de Guanambi se localiza no Semiárido Baiano, apresentando em média as seguintes características climáticas precipitação de 663,69 $\mathrm{mm}$, temperatura média de $26^{\circ} \mathrm{C}$ e umidade relativa do ar de $64 \%$.

Foram visitadas oito propriedades situadas no Povoado do Tanque, três no Povoado de Brejo dos Padres, três no Distrito de Morrinhos e uma no Distrito de Guirapá. As propriedades visitadas pertencem a pequenos produtores da região, com característica de agricultura familiar, tendo como base a produção de hortaliças, principalmente tomate de mesa. A variedade de tomate mais cultivada é a saladete. $\mathrm{Na}$ maioria das propriedades visitadas, havia duas ou três áreas plantadas com tomate em estágio diferente e todas essas áreas foram vistoriadas.

Durante as visitas, foram realizadas vistorias por todo o plantio, buscando diagnosticar a presença de sintomas de doenças de plantas. Observando-se a presença de sintomas característicos de doenças, as plantas foram fotografadas e coletadas partes da planta ou planta inteira, armazenadas em sacos plásticos e posteriormente levadas para o Laboratório de Fitopatologia do IFBaiano para diagnose.

Para ajudar no diagnóstico das doenças foram aplicados, durante as visitas, questionários aos produtores a fim de conhecer o histórico da área, os tratos culturais empregados, o controle fitossanitário e os cuidados com o uso dos agroquímicos. No questionário continha informações importantes sobre anatomia, fisiologia, tipo de sintomas, evolução dos sintomas na área, tratos culturais, tipo de irrigação, localização da lavoura, local da obtenção das sementes ou mudas, presença de assistência técnica, tipo de cultivar, entre outras.

No Laboratório de Fitopatologia do IFBaiano, a diagnose foi iniciada comparando-se os sintomas e sinais das doenças com a literatura, posteriormente o material vegetal infectado foi separado quanto aos grupos de doenças. As plantas com sintomas de doenças fúngicas foram submetidas à câmara úmida por $24 \mathrm{~h}$ para esporulação e posterior observação do micélio e esporos em microscópio. As plantas, com sintomas de murcha vascular, foram submetidas ao teste da corrida bacteriana em copo (MARTIN; FRENCH, 1985). As que apresentavam sintomas de doenças não identificadas ou com dúvidas quanto a sua identificação, foram enviadas para diagnóstico na Clínica Fitopatológica da USP/Esalq.

\section{RESULTADOS E DISCUSSÃO}

No levantamento de doenças do tomateiro foram encontradas nove doenças de origem biótica e três de origem abióticas causando diferentes sintomas e distúrbios fisiológicos, além da perda na qualidade do fruto e queda na produção. Foi observado que a ausência de assistência técnica na produção e no controle dos problemas fitossanitários contribui para gastos desnecessários com defensivos devido ao diagnóstico impreciso das doenças, intoxicação do agricultor com uso inadequado de agrotóxicos e queda na produção.

Dentre os 12 problemas fitossanitários encontrados no tomateiro na região, $59 \%$ foi de origem fúngica, $8 \%$ virótica, $8 \%$ bacteriana e $25 \%$ relacionado a fatores abióticos. A maior ocorrência de doenças fúngicas, confirma que os fungos são responsáveis pela maioria das doenças das hortaliças (REIS; 
BOITEUX, 2006). No levantamento foram diagnosticadas as seguintes doenças ocasionadas por fungos: murcha-de-fusário (Fusarium oxysporum), oídio (Oidium sp.), requeima (Phytophthora infestans), mofo preto (Alternaria alternata), mancha de estenfílio (Stemphylium sp.), mancha de cladospório (Fulvia fulva) e pinta-preta (Alternaria solani) (Tabela 01).

A murcha de fusário ( $F$. oxysporum f. sp. lycopersici) foi encontrada em três localidades visitadas (Tabela 1 e Figura C). Em uma das lavoras de tomate do Povoado de Brejo dos Padres, 50\% da área encontrava-se com sintomas típicos da murcha. Os sintomas da murcha-de-fusário encontrados no campo foram o amarelecimento das folhas mais velhas, murcha da planta e escurecimento dos tecidos vasculares infectados, observados com auxílio de um canivete. Observou-se que no povoado de Brejo dos Padres a incidência dessa doença é frequente e tem causado prejuízos aos produtores, que utilizam como forma de controle a rotação de cultura sem muito sucesso, pois se trata de uma doença de solo de fácil contaminação exigindo cuidados quanto á desinfestação de ferramentas e controle de movimentação de pessoas no local.

Tabela 01. Levantamento de doenças bióticas e abióticas do tomateiro na região de Guanambi, BA

\begin{tabular}{|c|c|c|c|c|}
\hline Localidade & Doença & Agente causal & $\begin{array}{c}\text { Frequência } \\
(\%)\end{array}$ & $\begin{array}{c}\text { Incidência } \\
(\%)\end{array}$ \\
\hline \multirow{9}{*}{$\begin{array}{l}\text { Povoado do } \\
\text { Tanque }\end{array}$} & Vira-cabeça & Tomato spotted wilt virus & 100 & $20-30$ \\
\hline & Murcha-de-fusário & Fusarium oxysporum & 20 & $1-10$ \\
\hline & Requeima & Phytophthora infestans & 20 & $1-10$ \\
\hline & Oídio & Oidium sp. & 20 & $1-10$ \\
\hline & Morfo preto & Alternaria alternata & 20 & ND \\
\hline & Mancha de estenfílio & Stemphylium sp. & 20 & ND \\
\hline & Podridão apical & Deficiência de cálcio & 100 & $10-20$ \\
\hline & Murcha por asfixia & Distúrbio fisiológico & 20 & $1-10$ \\
\hline & Doença fisiológica & Deficiência de fósforo & 30 & $20-30$ \\
\hline \multirow{3}{*}{$\begin{array}{l}\text { Distrito de } \\
\text { Morrinhos }\end{array}$} & Vira-cabeça & Tomato spotted wilt virus & 100 & $20-30$ \\
\hline & Oídio & Oidium sp. & 100 & $10-20$ \\
\hline & Podridão apical & Deficiência de cálcio & 100 & $20-30$ \\
\hline \multirow{6}{*}{$\begin{array}{l}\text { Povoado Brejo } \\
\text { dos Padres }\end{array}$} & Vira-cabeça & Tomato spotted wilt virus & 100 & $30-40$ \\
\hline & Pinta-preta & Alternaria solani & 50 & $20-30$ \\
\hline & Murcha-de-fusário & Fusarium oxysporum & 100 & $40-50$ \\
\hline & Oídio & Oidium sp. & 100 & $1-10$ \\
\hline & Podridão apical & Deficiência de cálcio & 50 & $20-30$ \\
\hline & Doença fisiológica & Deficiência de fósforo & 100 & $20-30$ \\
\hline \multirow{7}{*}{$\begin{array}{l}\text { Distrito de } \\
\text { Guirapá }\end{array}$} & Murcha bacteriana & Ralstonia solanacearum & 100 & ND \\
\hline & Mancha de estenfílio & Stemphylium sp. & 100 & ND \\
\hline & Mancha de cladospório & Fulvia fulva & 100 & ND \\
\hline & Murcha-de-fusário & Fusarium oxysporum & 100 & $1-10$ \\
\hline & Pinta-preta & Alternaria solani & 100 & $1-10$ \\
\hline & Podridão apical & Deficiência de cálcio & 100 & $20-30$ \\
\hline & Doença fisiológica & Deficiência de fósforo & 100 & $20-30$ \\
\hline
\end{tabular}

Frequência (\%): porcentagem de propriedades visitadas que apresentaram a doença. Incidência estimada (\%): porcentagem estimada de plantas com sintomas da doença. ND: Não determinada.

Houve presença de oídio (Oidium sp.) em três localidades visitadas, atacando as plantas, principalmente, no final do ciclo (Tabela 1). O sintoma do oídio nas lavouras de tomate caracterizou-se pela presença de estruturas do fungo na superfície superior das folhas deixado a aparência de um pó branco e fino. O controle dessa doença, segundo os agricultores, é feito com aplicações frequentes de fungicidas. Entretanto, foi observado que plantios novos de tomate e outras solanáceas eram instalados muito próximos de plantio velhos com alta infestação de oídio, facilitando sua disseminação, já que esse fungo é facilmente disseminado pelo vento. A presença constante de oídio nas lavouras se deve, provavelmente, a baixa umidade relativa do ar da região de Guanambi. Barroso et al. (2015), trabalhando com diagnóstico de doenças de plantas em hortas agroecológicas em Petrolina, PE, observaram que oídio e viroses foram as doenças que apresentaram maior ocorrência nos canteiros analisados.
A pinta-preta (A. solani) foi identificada no povoado Brejo dos Padres e Distrito de Guirapá com porcentagens de $20-30 \%$ e $1-10 \%$, respectivamente, de área infectada (Tabela 1 e Figura D). Os sintomas típicos da doença observados no campo foram frutos com podridão de cor escura na região peduncular. No caule, foram observadas manchas marrons arredondadas ou alongadas, muitas vezes com os anéis concêntricos bem visíveis.

A requeima ( $P$. infestans) foi observada apenas no Povoado do Tanque, apresentando porcentagem de 1-10\% de incidência da área (Tabela 1). Apesar das condições climáticas da região de Guanambi não serem favoráveis ao desenvolvimento dessa doença, que exige umidade relativa de 91 a 100\% para produção dos esporângios, houve diagnóstico dessa doença em algumas lavouras de tomate. Segundo Reis (2010), germinação direta dos esporângios em temperaturas relativamente altas, desde que haja temperaturas noturnas em torno de $22^{\circ} \mathrm{C}$, explica a ocorrência de surtos de requeima mesmo em regiões quentes, consideradas de baixo risco de 
requeima, como em alguns locais das Regiões Centro Oeste e Nordeste do Brasil. Viana et al. (2011), estudando a ocorrência de doenças em hortas comunitárias em sistema orgânico e sistema sem agrotóxico em Sete Lagoas, MG, observaram que as doenças que tiveram maior incidência foram míldio em alface e requeima e septoriose em tomate.

As doenças mofo preto dos frutos (Alternaria alternata), mancha-de-estenfílio (Stemphylium sp.), mancha de cladospório (Fulvia fulvum) foram identificadas nas amostras de plantas enviadas para a Clínica Fitopatológica, mas não foram diagnosticados sintomas na área (Tabela 1).

A virose causada pelo vira-cabeça-do-tomateiro (Tomato spotted wilt virus) foi encontrada em três localidades, ausente apenas no Distrito de Guirapá, apresentando cerca de 30-40\% da área infestada (Tabela 1 e Figura A). Sua distribuição na área encontrava-se tanto em reboleira como aleatória, principalmente em plantas jovens. No campo foram identificados os sintomas típicos da doença, citado por Kurozawa e Pavan (2005), como paralisação no desenvolvimento da planta, folhas distorcidas com lesões necróticas no limbo e pecíolo, brozeamento das folhas e o encarquilhamento do ponteiro da planta. Nos frutos infectados foi observado a formação de manchas distintas com anéis concêntricos.

Essa doença é relatada pelos agricultores como um dos mais graves problemas fitossanitários da região, devido seu comportamento devastador e irreversível, levando a prejuízos consideráveis. O controle em algumas propriedades é feito mediante o arranquio das plantas sintomáticas, além de pulverização com inseticidas para combater o inseto vetor.

Em relação as doenças bacterianas, foi encontrado apenas no Distrito de Guirapá a murcha bacteriana causada pela bactéria Ralstonia solanacearum. Essa bactéria foi identificada em pequena quantidade, em algumas amostras de plantas enviadas para clínica fitopatológica. Durante as visitas, não foi observado os sintomas típicos dessa doença nas lavouras, sugerindo-se que o clima da região, quente e seco, pode ter desfavorecido o seu desenvolvimento (Tabela 01).

Figura 01. Sintomas de doenças do tomateiro nas propriedades visitadas: (A) Vira-cabeça, (B) Podridão apical, (C) Murcha-de-fusário e (D) Pinta-preta.

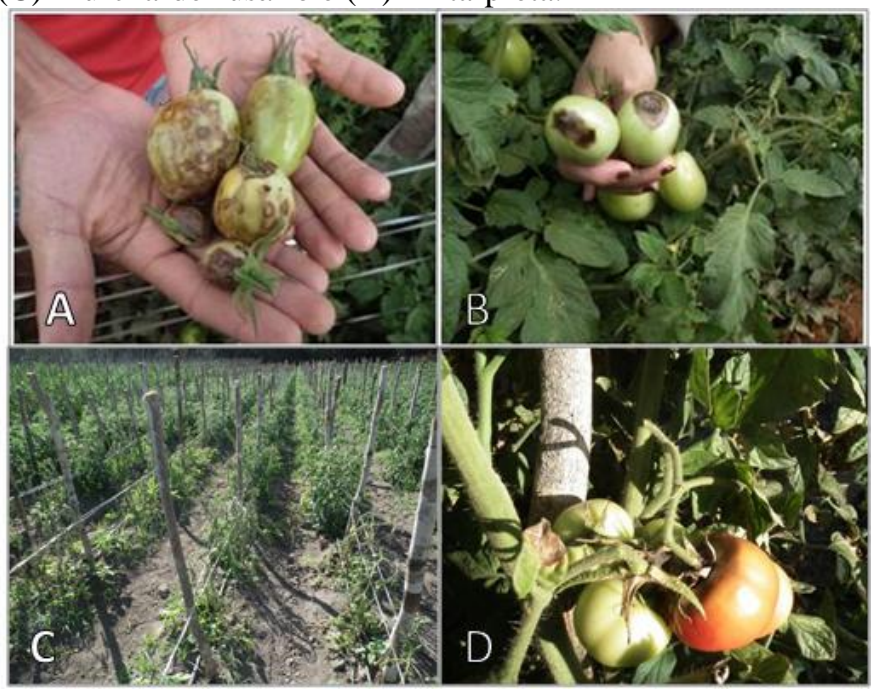

Distúrbios fisiológicos relacionados às deficiências nutricionais foram encontrados em, praticamente, todas as áreas visitadas. Distúrbios relacionados à deficiência de cálcio, expressos pela podridão apical dos frutos, foram observados em 20 a 30\% das plantas da lavoura (Tabela 1 e Figura B). A deficiência de fósforo, por sua vez, encontrada apenas no Distrito de Morrinhos, apresentou também porcentagem de 20 a 30\% de infestação nas áreas (Tabela 1).

Os sintomas de podridão apical (PA) dos frutos observados no campo correspondem aos encontrados na literatura, no qual se caracterizam pela presença de uma mancha sem bordas bem definidas na região apical, de cor marrom claro, tornando-se escura e deprimida de acordo à evolução do tamanho do fruto e seu consequente amadurecimento precoce (MELO et al., 2005; FILGUEIRA, 2008). A presença desse problema em todas as propriedades visitadas, possivelmente, se deve a deficiência de cálcio nas plantas associada a fatores ambientais. De acordo com Fontes (2003), interações entre irradiação, temperatura, disponibilidade de água, características físicas do solo, salinidade, balanço catiônico na solução do solo, resíduos no solo, umidade relativa do ar, entre outros, controlam o aparecimento de PA nos frutos. Segundo esse mesmo autor, não deve-se considerar a deficiência de cálcio como único fator responsável pela PA, uma vez que, é mais importante otimizar as condições edafoclimáticas e a quantidade dos insumos que maximizar a quantidade destes. Assim, práticas culturais como manejo adequado do solo; suprimento balanceado de nutrientes, principalmente do nitrogênio; baixa salinidade do solo; suprimento apropriado de água; plantio em condição de temperaturas amenas são exemplos de procedimentos, difíceis de serem otimizados, mas que, resultam em redução significativa de PA em tomate.

A deficiência de fósforo é expressa pelo arroxeamento das folhas. Tal deficiência retarda o crescimento das plantas e são mais notados em plantas jovens. As condições que favorecem a sua manifestação são: baixas temperaturas, compactação do solo, solo alcalino ou salino e adubação inadequada (MELO et al., 2005).

Os distúrbios fisiológicos causados pela deficiência nutricional ocorreram, possivelmente, devido ao preparo do solo inadequado, pois os agricultores não fazem análise química de solo, nem correção da acidez e fertilidade. A aplicação dos fertilizantes é feita apenas baseada na necessidade da cultura. Os agricultores relataram que a PA é um dos problemas mais graves do tomateiro, e muitas vezes causam prejuízos consideráveis. No inicio do aparecimento dos sintomas os agricultores aplicam cálcio foliar na tentativa de corrigir o desequilíbrio nos próximos frutos.

As análises das amostras recolhidas do Povoado de Tanque, realizadas pela clínica fitopatológica confirmaram também a presença do distúrbio fisiológico conhecido como murcha por asfixia (Tabela 1). Na propriedade onde se retirou esta amostra foi observado um vazamento no tubo de irrigação tornando o solo encharcado, favorecendo o aparecimento desta doença.

De acordo com o observado durante as visitas, é perceptível a carência de orientações técnicas na forma de cursos, palestras, dias de campo, entre outros, os quais possam capacitar os produtores quanto à necessidade de adotar novas técnicas de manejo, que visem à utilização mais 
racional e eficiente da água, fertilizante e defensivos e, principalmente, a preservação do meio ambiente.

Este é o primeiro relato da ocorrência de doenças do tomateiro na região de Guanambi, BA. Estas informações servirão de base para futuros trabalhos de pesquisa e extensão e para auxiliar no estabelecimento de medidas de controle, que visem reduzir os danos causados por essas doenças na região.

\section{CONCLUSÕES}

Foram diagnosticadas nove doenças bióticas - murchade-fusário (Fusarium oxysporum), oídio (Oidium sp.), requeima (Phytophthora infestans), morfo preto (Alternaria alternata), mancha de estenfílio (Stemphylium sp.), mancha de cladospório (Fulvia fulva), pinta-preta (Alternaria solani), vira cabeça do tomateiro (Tomato spotted wilt virus) e murcha bacteriana (Ralstonia solanacearum) - e três doenças abióticas - podridão apical, deficiência de fósforo e murcha por asfixia - nos cultivos de tomate.

Dentre as doenças bióticas encontradas, o vira cabeça do tomateiro (Tomato spotted wilt virus) e o oídio (Oidium sp.) foram as mais frequentes.

\section{AGRADECIMENTOS}

Aos alunos Elismar Pereira de Oliveira e Joabe da Silva Souza por ajudar na localização das propriedades agrícolas.

\section{REFERÊNCIAS BIBLIOGRÁFICAS}

BARROSO, K.A.; CAPUCHO, A.S.; GERVÁSIO, R.C.G; SILVA, S.D.P.; ROCHA, A.M.S.R. Diagnóstico de doenças de plantas em hortas agroecológicas em Petrolina-PE. Extramuros - Revista de extensão da UNIVASF, v.3 n.1, p.146-148, 2015.

FILGUEIRA, F.A.R. Novo Manual de Olericultura: agrotecnologia moderna na produção e comercialização de hortaliças.Viçosa, MG: Editora UFV, 2008, 421p.

FONTES, P.C.R. Podridão apical do tomate, queima dos bordos das folhas em alface e depressão amarga dos frutos em maçã: deficiência de Ca? Horticultura Brasileira, Brasília, v.21, n.2, p. 144, abril/junho, 2003.

IBGE - Instituto Brasileiro de Geografia e Estatística. Produção Agrícola Municipal: culturas temporárias e permanentes. Rio de Janeiro, v.40, 2013, 102p.
KUROZAWA, C.; PAVAN, M.A. Doenças do tomateiro (Lycopersicon esculentum) In: KIMATI, H.; AMORIM, L.; REZENDE, J.A.M.; BERGAMIN FILHO, A.; CAMARGO, L.E.A. Manual de Fitopatologia: doenças das plantas cultivadas. São Paulo: Ceres, v.2, 2005, p. 607-626.

LEAL, M.A.A; GUERRA, J.G.M; PEIXOTO, R.T.G; ALMEIDA, D.L. Utilização de compostos orgânicos como substratos na produção de mudas de hortaliças. Horticultura Brasileira, v.25, p.392-395, 2007.

MARTIN, C.; FRENCH, E.R. Bacterial wilt of potato. Peru, International Potato Center, 1985, 16p.

MELO, P.C.T.; LOPES, C.A.; GIORDANO, L.B. Distúrbios fisiológicos. In: LOPES, C.A.; ÁVILA, A.C. Doenças do tomateiro, Brasília: Embrapa Hortaliças, p. 101-132. 2005.

POZZA, E.A.; SOUZA, P.E.; CASTRO, H.A.; POZZA, A.A.A. Frequência da ocorrência de doenças da parte aérea de plantas na região de Lavras-MG. Ciência e Agrotecnologia, Lavras, v.23, n.4, p.1001-1005, 1999.

REIS, A. Requeima: doença destrutiva e comum ao tomateiro e à batateira. Brasília: Embrapa 2010, 7 p. (Comunicado Técnico, 78).

REIS, A.; BOITEUX, L.S. Murcha - de - verticillium: um sério problema para o cultivo de hortaliças no Brasil. Circular Técnica, n.40, Brasília, 2006.

REZENDE, J.A.M.; MASSOLA JR., N.S.; BEDENDO, I.P.; KRUGNER, T.L. Conceitos de doença, sintomatologia e diagnose. In: AMORIM, L.A.; REZENDE, J.A.M.; BERGAMIN FILHO, A. (Eds.) Manual de Fitopatologia: princípios e conceitos. Piracicaba: Ceres, v.1., 2011, p.3758 .

SANTOS, J.C.S.; SIQUEIRA, W.J.; MELO, P.C.T.; COLARICCIO, A.; LOURENÇÃO, A.L.; MELO, A.M.T. Selection of tomato breeding lines with resistance to Tomato yellow vein streak virus. Horticultura Brasileira, v. 33, n.3, p.345-351, 2015.

VIANA, M.M.S.; FERRAZ, L.C.L.; OLIVEIRA, G.B.Z.; SILVA, E.C. Ocorrência de doenças em hortaliças cultivadas comunitariamente em sistema orgânico e SAT em Sete Lagoas-MG. Cadernos de Agroecologia, v.6, n.2, 2011. 